\title{
Cycle length of nonsustanied ventricular tachycardias among ICD patients: implications on subsequent appropriate therapies
}

\author{
Javier Jiménez-Candil", Olga Duran, Armando Oterino, Jendri Pérez, Juan Carlos Castro, Jesús Hernández,
} José Morínigo, Manuel Sánchez García and Pedro L. Sánchez

\begin{abstract}
Background: ICD patients with episodes of nonsustained ventricular tachycardias (NSVT) are at risk of appropriate therapies. However, the relationship between the cycle length $(\mathrm{CL})$ of such NSVTs and the subsequent incidence of appropriate interventions is unknown.
\end{abstract}

Methods: 416 ICD patients with LVEF < 45\% were studied. ICD programming was standardized. NSVT was defined as any VT of 5 or more beats at $\geq 150$ bpm occurred in the first 6 months after implantation that terminated spontaneously and was not preceded by any appropriate therapy. The mean follow-up was $41 \pm 27$ months.

Results: We analyzed 2201 NSVTs (mean $C L=323 \mathrm{~ms}$ ) that occurred in 250 patients; 111 of such episodes were fast $(\mathrm{CL} \leq 300 \mathrm{~ms})$. Secondary prevention $(\mathrm{HR}=1.7 ; p<0.001)$, number of NSVT episodes $(\mathrm{HR}=1.05 ; 95 \% \mathrm{Cl} 1.04-1.07$; $p<0.001)$ and beta-blocker treatment $(\mathrm{HR}=0.7 ; p=0.04)$ were independent predictors of appropriate interventions; however, the mean CL of NSVTs was not $(p=0.6)$. There was a correlation between the mean CL of NSVTs and the $\mathrm{CL}$ of the first monomorphic VT: $r=0.88 ; p<0.001$. This correlation was especially robust in individuals with $>5$ NSVTs $(r=0.97 ; p<0.001)$, with an agreement between both values greater than 95\%. Patients with any fast NSVT experienced a higher incidence of VF episodes (26\%) compared to those without NVSTs (3\%) or with only slow NSVTs (7\%); $p<0.001$

Conclusions: Unlike the burden, the CL of NSVTs is not a predictor of subsequent appropriate interventions. However, there is a close relationship between the CL of NSVTs and that of arrhythmias that will later lead to appropriate therapies.

Keywords: Implantable cardioverter-defibrillator, Ventricular tachycardia, Appropriate therapy

\section{Introduction}

Episodes of nonsustained ventricular tachycardia (NSVT) are frequently observed in subjects with left ventricular systolic dysfunction and heart failure [1, 2]. Among ICD patients, the prevalence of such episodes ranges from 20

*Correspondence: jimenezcandil@secardiologia.es Arrhythmias Unit, Cardiology Department, IBSAL-University Hospital, CIVER-CV, Universidad de Salamanca, Paseo de San Vicente, 58-182, 37007 Salamanca, Spain to $60 \%$ [3-5], depending on the duration of monitoring, detection criteria and clinical context.

Several groups have reported that subjects with NSVTs over a wide range of cycle length (CL), are at higher adjusted risk of appropriate therapies $[3,5,6]$ the risk being highest in those with a greater burden, defined as more than 5 episodes in the six months following the implant [4]. However, we do not have updated information on the relationship between the CL of NSVTs and the therapies subsequently applied by ICDs. This

(c) The Author(s) 2021. Open Access This article is licensed under a Creative Commons Attribution 4.0 International License, which permits use, sharing, adaptation, distribution and reproduction in any medium or format, as long as you give appropriate credit to the original author(s) and the source, provide a link to the Creative Commons licence, and indicate if changes were made. The images or other third party material in this article are included in the article's Creative Commons licence unless indicated otherwise in a credit line to the material. If material is not included in the article's Creative Commons licence and your intended use is not permitted by statutory regulation or exceeds the permitted use, you will need to obtain permission directly from the copyright holder. To view a copy of this licence, visit http://creativecommons.org/licenses/by/4.0/. The Creative Commons Public Domain Dedication waiver (http://creativeco mmons.org/publicdomain/zero/1.0/) applies to the data made available in this article, unless otherwise stated in a credit line to the data. 
sub-analysis of our previously published experience [4] aims to determine the ability of CL of NSVT episodes (identified upon ICD interrogation during the first 6 months after implant) to predict the incidence and characteristics of tachycardias that will subsequently produce appropriate therapies.

\section{Methods}

\section{Study population}

Patients with left ventricular dysfunction $(\mathrm{LVEF}<45 \%)$ and an ICD, implanted according to standard indications and without Cardiac Resynchronization Therapy, were studied [4]. Subjects were consecutively enrolled from January 2006 through to December 2013 and were followed up until June 2014. Vital status was available for $100 \%$ of the individuals at the end of the follow-up period, and patient recruitment was carried out at the time of ICD implantation.

The study complied with the Declaration of Helsinki. Enrolment of the patients followed once the protocol had been approved by the institutional review board, and informed consent was obtained from all patients.

\section{ICD programming}

Detection and therapy programming were standardized and included three zones: ventricular fibrillation (VF): cycle length $(\mathrm{CL})<250 \mathrm{~ms}$, ventricular tachycardia zone 1 (fast VT): CL from 250 to $320 \mathrm{~ms}$, and ventricular tachycardia zone 2 (slow VT): CL from 321 to $400 \mathrm{~ms}$.

In the case of the Medtronic devices, Ventricular Fibrillation detection required that 18 of the last $24 \mathrm{R}-\mathrm{R}$ intervals had a cycle length $(\mathrm{CL})$ of $<250 \mathrm{~ms}(>240 \mathrm{bpm})$. The fast VT detection zone was defined within the VF zone (fast VT zone via ventricular fibrillation). When any of the final $8 \mathrm{R}-\mathrm{R}$ intervals preceding the moment of detection was $<250 \mathrm{~ms}(>240 \mathrm{bpm})$, the episode was classified as VF and received a high energy shock. When all of the last $8 \mathrm{R}-\mathrm{R}$ intervals were $>250 \mathrm{~ms}(<240 \mathrm{bpm})$, the episode was detected as fast VT, and slow VT detection required 16 consecutive intervals.

For the Boston Scientific devices, the episodes were detected when 8 out of 10 RR intervals had a CL within the detection interval, and at least 6 out of every $10 R R$ intervals were within the predefined limits for VT detection, during the subsequent $2.5 \mathrm{~s}$ in fast and $5 \mathrm{~s}$ in slow VT.

Starting from 1 January 2013, the detection criteria were modified to $30 / 40$ for fast VT and 40 consecutive RR intervals for slow VT (for the Medtronic devices), and to 8 (fast VT) and $16 \mathrm{~s}$ (slow VT) for the Boston Scientific devices.

The first ATP therapy in the fast VT zone was a single antitachycardia pacing (ATP) sequence (5-pulse-burst pacing train at $84 \%$ of the VT CL) and failed ATP was followed by a shock and then additional shocks, as necessary. Therapies for slow VT included 3 consecutive ATP bursts of 15 pulses at $91 \%$ of the VT CL, with no decrement. Failed ATP was followed by a sequence of shocks.

Additional criteria (onset, stability and morphology) were programmed in the slow VT zone. All devices were programmed to store the far-field electrogram before the onset of the detected episodes to aid in rhythm classification. In the Medtronic devices the "Smart mode" was programmed to "off".

All tip-to-ring- and far-field-stored electrograms from spontaneous episodes were classified using predetermined criteria based on visual inspection and comparison with sinus rhythm electrograms [7, 8]. Classification of ventricular and supraventricular tachycardias was performed by two independent investigators, and a third investigator was consulted in cases where there was a lack of consensus.

\section{Definitions}

NSVT was defined as any ventricular tachyarrhythmia with $>5$ beats at $\geq 150 \mathrm{bpm}$ terminating spontaneously before therapy that occurred within the first six months after ICD implant and which was not preceded by any arrhythmia causing appropriate therapy. Monomorphic VT (MVT) required a stable morphology of the electrogram, whereas in VF the morphology was changing beat to beat, with a $\mathrm{CL}<250 \mathrm{~ms}$.

\section{Statistical analyses}

Statistical analysis was performed using the 25 version for Windows (SPSS Inc., Chicago, Illinois). Normal and continuous variables were described by mean and $95 \%$ confidence interval (CI) or standard deviation, whereas categorical variables were summarized by the number of patients and percentage. Comparison of the categorical variables was performed with the Chi-square test (or Fisher's exact test if $\mathrm{n}<5$ ). Comparison of 2 normal variables (determined by the Kolgomorov-Smirnov test) and continuous variables was done using the Student's t test. Comparison of $>2$ continuous variables was performed using the ANOVA test.

To determine both the mean CL of NSVTs and MVT episodes, adjusted for multiple episodes per patient, the Generalized Estimating Equations Method (GEEM) was used in the calculations and comparisons [9].

The quantification of the linear relationship between two quantitative variables was studied by calculating the Pearson's correlation coefficient ( $r$ Coefficient). The Bland-Antman method was used to evaluate the agreement between the values of two quantitative variables. Comparisons of cumulative incidences were carried 
out using the log-rank test. Univariate and multivariate Cox proportional hazards regression analysis was used to evaluate the contribution of baseline clinical factors [age, gender, diabetes, left ventricular ejection fraction, functional class (NYHA), etiology (ischemic vs. nonischemic), indication (primary vs. secondary prevention), QRS duration (ms), atrial fibrillation, body mass index, serum creatinine $(\mathrm{mg} / \mathrm{dl})$, medical treatments (including amiodarone), burden of NSVTs and CL of NSVTs] to the occurrence of appropriate therapies, appropriate shocks, appropriate therapies due to MVT and appropriate therapies due to VF. Univariate variables with a $p<0.1$ were included in a multivariate Cox-regression model. A $p$ value $<0.05$ was considered significant.

\section{Results}

\section{Patients, follow-up and appropriate therapies}

A total of 416 patients were consecutively studied. Their baseline characteristics are displayed in Table 1. They were followed for a mean of $41 \pm 27$ months from ICD implant.
During follow-up, 1491 appropriate therapies (1441 due to monomorphic VT [MVT] and 50 due to VF) were recorded in 190 patients. Figure 1 . Of the total of appropriate therapies, there were 439 shocks that occurred in $113(27 \%)$ subjects.

\section{NSVT episodes occurring early}

A total of 2335 episodes of NSVTs were documented during the first 6 months following ICD implant. After excluding 134 episodes that lacked stored electrograms, we analyzed 2201 NSVTs ( $10+7$ beats), which occurred in 250 of the 416 patients. The median number of NSVTs per patient was $2(\mathrm{IQR}=0-7)$. Patients were classified into three groups according to the tertiles of the NSVTs burden: zero $(n=166), 1-5(n=130)$ and $>5(n=120)$. Table 1.

\section{Cycle length of NSVT}

The adjusted mean CL of NSVTs was $323 \mathrm{~ms}$ (95\% CI 318-328). One hundred and eleven NSVTs had a $\mathrm{CL} \leq 300 \mathrm{~ms}$; they occurred in 27 patients.

Table 1 Baseline characteristics and outcomes of patients according to the episodes of nonsustained ventricular tachycardia

\begin{tabular}{|c|c|c|c|c|c|}
\hline Variable & $\begin{array}{l}\text { All patients } \\
n=416\end{array}$ & $\begin{array}{l}\text { Patients without } \\
\text { episodes } \\
n=166(40)\end{array}$ & $\begin{array}{l}\text { Patients with } 1-5 \\
\text { episodes } \\
n=130(31)\end{array}$ & $\begin{array}{l}\text { Patients with }>5 \\
\text { episodes } \\
n=120 \text { (29) }\end{array}$ & $p$ value \\
\hline Age, years & $65 \pm 11$ & $63 \pm 12$ & $65 \pm 12$ & $69 \pm 9$ & $<0.001^{\dagger}$ \\
\hline Male gender & $87 \%$ & $87 \%$ & $88 \%$ & $87 \%$ & $0.9^{*}$ \\
\hline Ischemic etiology & $62 \%$ & $63 \%$ & $62 \%$ & $63 \%$ & $0.8^{*}$ \\
\hline Secondary prevention & $37 \%$ & $35 \%$ & $38 \%$ & $37 \%$ & $0.8^{*}$ \\
\hline Atrial fibrillation & $22 \%$ & $15 \%$ & $20 \%$ & $32 \%$ & $0.002^{*}$ \\
\hline New York Heart Association Functional Class > 1 & $63 \%$ & $56 \%$ & $64 \%$ & $71 \%$ & $0.036^{*}$ \\
\hline Diabetes & $25 \%$ & $28 \%$ & $22 \%$ & $24 \%$ & $0.5^{\dagger}$ \\
\hline Left ventricular ejection fraction (\%) & $30 \pm 8$ & $30 \pm 8$ & $30 \pm 9$ & $30 \pm 7$ & $0.8^{\dagger}$ \\
\hline QRS duration (ms) & $118 \pm 24$ & $114 \pm 23$ & $120 \pm 22$ & $121 \pm 26$ & $0.018^{\ddagger}$ \\
\hline Serum creatinine (mg/dl) & $1.22 \pm 0.48$ & $1.15 \pm 0.33$ & $1.22 \pm 0.37$ & $1.32 \pm 0.7$ & $0.012^{\dagger}$ \\
\hline Previous clinical nonsustained ventricular tachycardias & $36 \%$ & $11 \%$ & $39 \%$ & $51 \%$ & $<0.001^{*}$ \\
\hline Statins & $62 \%$ & $63 \%$ & $61 \%$ & $59 \%$ & $0.7^{*}$ \\
\hline Beta-blockers & $76 \%$ & $83 \%$ & $82 \%$ & $70 \%$ & $0.011^{\S}$ \\
\hline $\begin{array}{l}\text { Angiotensin Converting Enzyme Inhibitors or Angiotensin } \\
\text { ॥ Receptor Blockers }\end{array}$ & $86 \%$ & $86 \%$ & $85 \%$ & $89 \%$ & $0.7^{*}$ \\
\hline Amiodarone & $13 \%$ & $8 \%$ & $15 \%$ & $20 \%$ & $0.011^{*}$ \\
\hline Digoxin & $18 \%$ & $9 \%$ & $22 \%$ & $25 \%$ & $0.001 \|$ \\
\hline Appropriate therapy & $46 \%$ & $27 \%$ & $48 \%$ & $70 \%$ & $<0.001^{9}$ \\
\hline Appropriate therapy due to MVT & $44 \%$ & $26 \%$ & $45 \%$ & $66 \%$ & $<0.001^{\natural}$ \\
\hline Appropriate therapy due to VF & $6.5 \%$ & $3 \%$ & $7 \%$ & $12 \%$ & $0.026^{\prime \prime}$ \\
\hline Appropriate shock & $27 \%$ & $16 \%$ & $25 \%$ & $44 \%$ & $<0.001^{9}$ \\
\hline Cardiac mortality & $17 \%$ & $7 \%$ & $18 \%$ & $32 \%$ & $<0.001^{n}$ \\
\hline
\end{tabular}

Patients are classified according to the tertiles of NSVT episodes

${ }^{*}$ Chi-square test for trend; ${ }^{\dagger}$ ANOVA for all comparisons; ${ }^{*}$ first group versus others, ANOVA test; ${ }^{\S}$ third tertile versus others, Chi-squared test; "lfirst group versus others,

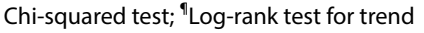




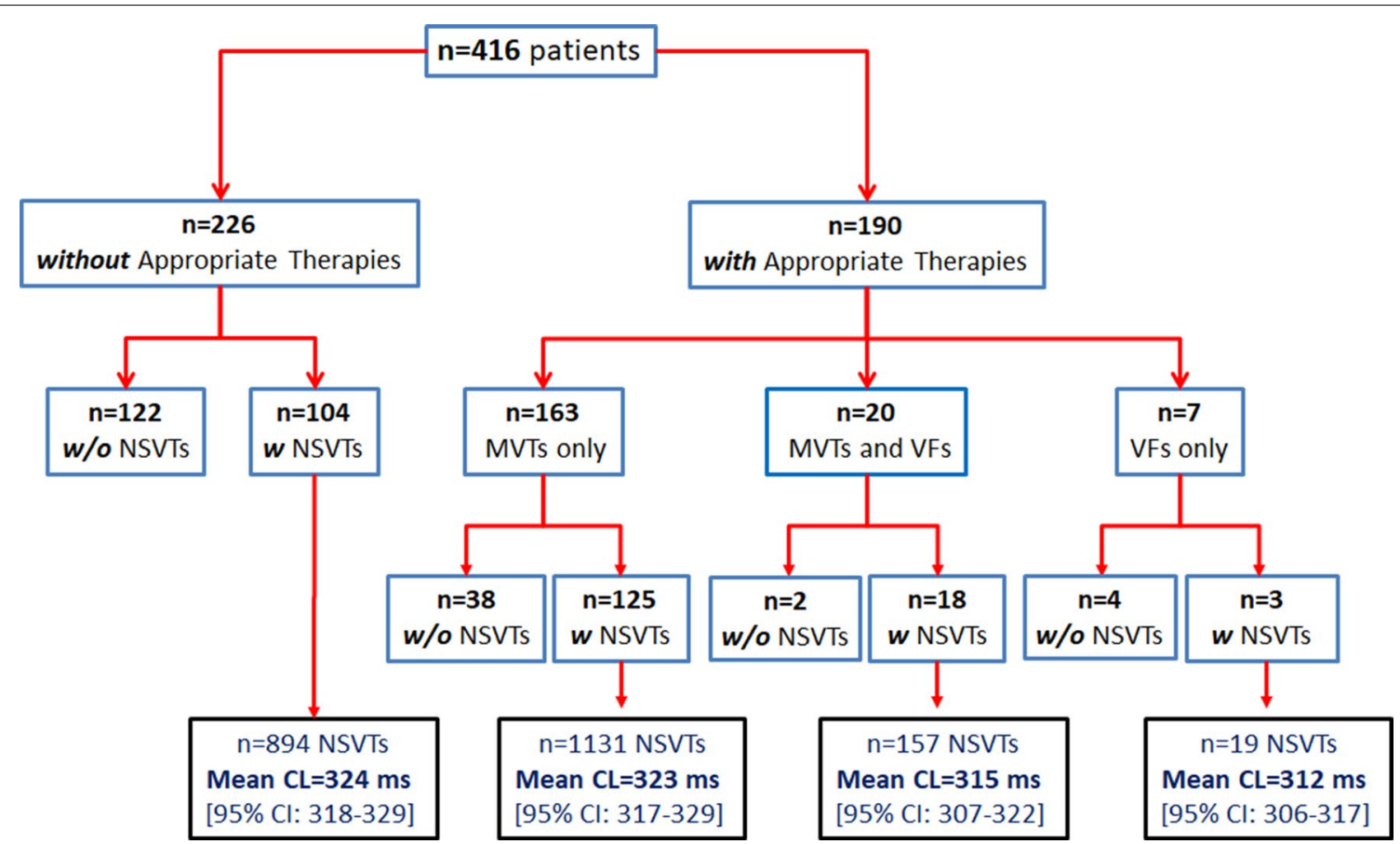

Fig. 1 Diagram showing the relationship between the incidence of appropriate therapies (and their index arrhythmia) with the CL of preceding NSVT episodes

As shown in Table 2, the adjusted mean CL of unsustained episodes was significantly lower in primary prevention patients and in those with $>5$ episodes. In contrast, the CL of NSVT episodes was longer in subjects under beta-blocker treatment. We found no differences in the mean CL of NSVTs depending on the etiology, functional class or severity of the left ventricular dysfunction.

\section{Predictors of electrical therapies among subjects with NSVT}

The mean CL of NSVTs was similar in patients with or without appropriate therapies and appropriate shocks (Table 2).

Secondary prevention $(\mathrm{HR}=1.7 ; 95 \%$ CI 1.3-2.3; $p<0.001$ ), burden of NSVT episodes ( $\mathrm{HR}=1.05 ; 95 \%$ CI $1.04-1.07 ; p<0.001)$ and beta-blocker treatment $(\mathrm{HR}=0.7 ; 95 \% \mathrm{CI} 0.5-0.9 ; p=0.04)$ were associated

Table 2 Adjusted mean CL of NSVT episodes according to different variables

\begin{tabular}{lll}
\hline Variable & Mean adjusted CL of NSVT episodes ${ }^{\mathbf{a}}$, ms & Statistical analysis \\
\hline Ischemic etiology & $323(95 \% \mathrm{Cl} 319-327)$ versus $324(95 \% \mathrm{Cl} 318-328)$ & $95 \% \mathrm{Cl}$ of the difference $(-3 ; 5) p=0.7$ \\
Primary prevention & $320(95 \% \mathrm{Cl} 318-323)$ versus $327(95 \% \mathrm{Cl} 321-330)$ & $95 \% \mathrm{Cl}$ of the difference $(2 ; 10) p=0.008$ \\
LVEF $\leq 35 \%$ & $324(95 \% \mathrm{Cl} 319-328)$ versus $320(95 \% \mathrm{Cl} 316-327)$ & $95 \% \mathrm{Cl}$ of the difference $(-4 ; 3) p=0.2$ \\
Functional class $>1(\mathrm{NYHA})$ & $324(95 \% \mathrm{Cl} 319-328)$ versus $322(95 \% \mathrm{Cl} 317-326)$ & $95 \% \mathrm{Cl}$ of the difference $(-7 ; 2) p=0.2$ \\
Beta-blocker treatment & $326(95 \% \mathrm{Cl} 322-330)$ versus $316(95 \% \mathrm{Cl} 309-321)$ & $95 \% \mathrm{Cl}$ of the difference $(5 ; 14) p<0.001$ \\
$>5$ NSVT episodes & $321(95 \% \mathrm{Cl} 317-325)$ versus $325(95 \% \mathrm{Cl} 320-330)$ & $95 \% \mathrm{Cl}$ of the difference $(-10 ;-2) p=0.004$ \\
$\geq 1$ appropriate therapies & $322(95 \% \mathrm{Cl} 317-328)$ versus $324(95 \% \mathrm{Cl} 318-329)$ & $95 \% \mathrm{Cl}$ of the difference $(-2 ; 3) p=0.3$ \\
$\geq 1$ appropriate shocks & $322(95 \% \mathrm{Cl} 318-326)$ versus $325(95 \% \mathrm{Cl} 320-329)$ & $95 \% \mathrm{Cl}$ of the difference $(-1 ; 6) p=0.2$ \\
$\geq 1$ appropriate therapies due to MVT & $322(95 \% \mathrm{Cl} 319-327)$ versus $324(95 \% \mathrm{Cl} 319-328)$ & $95 \% \mathrm{Cl}$ of the difference $(-3 ; 4) p=0.3$ \\
$\geq 1$ appropriate therapies due to VF & $314(95 \% \mathrm{Cl} 308-321)$ versus $324(95 \% \mathrm{Cl} 320-328)$ & $95 \% \mathrm{Cl}$ of the difference $(-18 ;-4) p=0.002$
\end{tabular}

LVEF left ventricular ejection fraction, NYHA New York Heart Association, NSVT non-sustained ventricular tachycardia, MVT MONOMORPHIC VENTRICULAR tachycardia, vf ventricular fibrillation

${ }^{a}$ Variable present versus variable absent 
independently with the incidence of appropriate therapies. The same variables appeared as independent predictors of appropriate shocks: secondary prevention $(\mathrm{HR}=2.2$; 95\% CI 1.6-3.2; $p<0.001)$, burden of NSVTs $(\mathrm{HR}=1.04 ; 95 \% \mathrm{CI} 1.02-1.06 ; p<0.001)$ and beta-blocker treatment $(\mathrm{HR}=0.6 ; 95 \% \mathrm{CI} 0.4-0.9 ; p=0.04)$. However, the CL of NSVTs was not a predictor of either appropriate interventions $(\mathrm{HR}=0.4 ; 95 \% \mathrm{CI}=0.4-1.5 ; p=0.6)$ or appropriate shocks $(\mathrm{HR}=0.5 ; 95 \% \mathrm{CI}=0.3-1.6 ; p=0.4)$.

As shown in Table 3, the burden of NSVTs per patient maintained its independent predictive capacity on the incidence of appropriate therapies over the whole spectrum of $C L$ values.

\section{Appropriate therapies due to monomorphic VT}

The 1441 MVT occurred in 183 patients. Figure 1. The mean CL of MVT was 335 ms (95\% CI interval 324340). There were 446 (31\%) fast VT episodes with a $\mathrm{CL} \leq 320 \mathrm{~ms}$ that occurred in 97 (23\%) individuals. As shown in Table 2, the mean CL of NSVTs was similar in patients with or without appropriate therapies due to MVT. By multivariate analysis (Cox-regression), the indication for secondary prevention $(\mathrm{HR}=1.6 ; 95 \% \mathrm{CI}=1.2-$ 2; $p=0.4)$ and a NSVT burden $>5$ episodes $(\mathrm{HR}=2$; 95\% $\mathrm{CI}=1.6-2$.; $p=0.002$ ) appeared to be independent predictors of appropriate therapies due to MVT. However, neither the beta-blocker treatment ( $\mathrm{HR}=0.7 ; 95 \%$ $\mathrm{CI}=0.5-1.06 ; p=0.1)$ nor the mean $\mathrm{CL}$ of the NSVT episodes $(\mathrm{HR}=0.5 ; 95 \% \mathrm{CI}=0.4-1.5 ; p=0.5)$ reached statistical significance.

Among patients who presented NSVT and MVT episodes $(n=143)$, we analyzed the relationship between the adjusted mean CL of the NSVTs ( $\mathrm{n}=1288$ episodes) and the CL of the first appropriate therapy due to MVT occurring subsequently. Although the mean CL was shorter in NSVT [324 ms (95\% CI 320-227)] compared to MVT episodes [330 ms (95\% CI 326-334)], we found a significant correlation between the two (Fig. 1, left), with similar robustness in individuals with ischemic ( $r$

Table 3 Adjusted hazard ratio of NSVT burden according to the mean $\mathrm{CL}$ of the episodes (adjusted for multiples episodes per patients, GEEM)

\begin{tabular}{lccc}
\hline $\begin{array}{l}\text { Mean CL of NSVTs } \\
(\mathbf{m s})\end{array}$ & $\begin{array}{l}\text { Number of } \\
\text { patients }\end{array}$ & HR $(\mathbf{9 5} \% \mathrm{Cl})$ & $\boldsymbol{p}$ value \\
\hline$\leq 310$ & 58 & $1.06(1.01-1.12)$ & 0.03 \\
$311-330$ & 156 & $1.05(1.03-1.08)$ & $<0.001$ \\
$331-400$ & 36 & $1.07(1.02-1.13)$ & 0.012 \\
\hline
\end{tabular}

Multivariate Cox proportional hazards regression analysis

NSVT nonsustained ventricular tachycardia, $C L$ cycle length, GEEM generalized estimating equations method, $H R$ hazard ratio, $\mathrm{Cl}$ confidence interval coefficient $=0.86 ; \mathrm{n}=90)$ versus non-ischemic cardiomyopathy $(r=0.90 ; n=543$, and in primary $(r=0.86$; $\mathrm{n}=73)$ versus secondary prevention $(\mathrm{r}=0.90 ; \mathrm{n}=70)$. The strongest correlation was observed in subjects with $>5$ NSVTs, as shown in Fig. 2.

We also analyzed the agreement between both values. The difference between the two values was $2 \pm 8.3 \mathrm{~ms}$, with only $7.6 \%(11 / 145)$ of patients in whom the difference between the two CL was outside the concordance limits. The agreement was greater, again, in individuals with $>5$ NSVTs. As shown in Fig. 3, in more than 95\% of such patients both values were within the interval of agreement $(0.32 \pm 4 \mathrm{~ms})$.

\section{Appropriate therapies due to VF}

Fifty episodes of VF occurred during the follow-up in $27(6.5 \%)$ patients; of these, 21 presented at least one NSVT. Figure 1. As shown in Table 1, the cumulative incidence of VF increased according to the NSVTs burden.

The adjusted mean CL of the NSVTs was significantly lower in subjects with episodes of VF. Table 2. By multivariate analysis, the adjusted mean CL of NSVT episodes was the only independent predictor of appropriate therapies due to VF: $\mathrm{HR}=0.97$ (95\% CI 0.95-0.99); $p<0.005$. Neither the burden of NSVTs $>5$ episodes $(\mathrm{HR}=1.6$; 95\% CI 0.6-4.2; $p=0.3$ ) nor the beta-blocker treatment $(\mathrm{HR}=0.5 ; 95 \% \mathrm{CI} 0.2-1.1 ; p=0.1)$, nor the indication for secondary prevention $(\mathrm{HR}=1.6$; $95 \%$ CI $0.7-3.6$; $p=0.3$ ) reached statistical significance. As shown in Fig. 4, patients with at least one fast episode of NSVT $(\mathrm{CL} \leq 300 \mathrm{~ms}$ ) experienced a higher incidence of appropriate therapies due to VF.

\section{Discussion \\ Main findings}

In this work we have analyzed the relationship between the CL of NSVTs episodes occurring early (i.e., in the first six months after implantation of an ICD) and the arrhythmias underlying the therapies applied by the devices. The main findings of this study are: (1) unlike the burden, the CL of NSVT episodes occurring early after an ICD implantation is not an independent predictor of appropriate therapies; (2) the CL of the first MVT causing appropriate therapy is closely related to the adjusted mean CL of precedent NSVT episodes and such relationship (expressed as a significant correlation and concordance) is especially robust in patients with more than 5 NSVTs; and (3) patients who present with fast episodes of NSVTs are at significantly increased risk of appropriate therapies due to VF. 


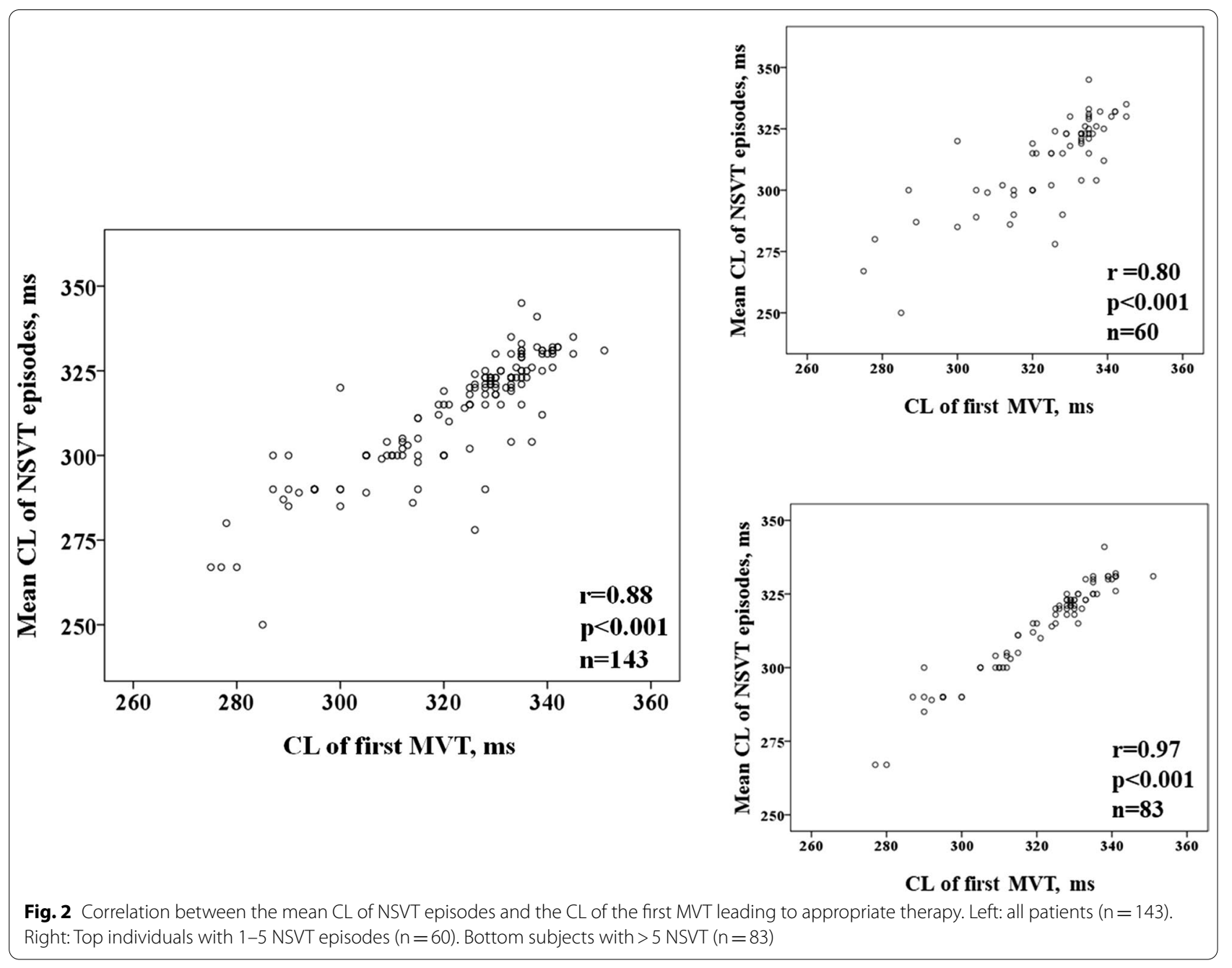

\section{NSVT episodes and electrical therapies}

The occurrence of episodes of NSVT in subjects with left ventricular dysfunction is associated with an increase risk in arrhythmic events. This is true both for NSVTs observed during continuous ambulatory ECG monitoring [10] and for their documentation during ICDs interrogation [3]. Although there are few updated data on myocardial tissue characterization, it has classically been assumed that, in subjects with ischemic heart disease, the electrophysiological substrate of subjects with only episodes of NSVT, sustained MVT or VF is different. Therefore, both the presence of pathological electrograms is more frequent and the endocardial activation time of the left ventricle is longer in individuals with MVT [11]. In addition, regardless of etiology, it is assumed that reentry is the mechanism underlying the vast majority of MVTs among subjects with scars and ventricular dysfunction [12].

The arrhythmogenic substrate in subjects with myocardial scars is not stable, but progresses over time [13], which may justify the clinical evolution from nonsustained to sustained forms of VT [14]. In this line, Elin et al. have shown the existence of a significant association between the induction of NSVTs after catheter ablation and the recurrence of sustained MVT [15]. In addition, different burdens of unsustained tachycardias may correspond to different degrees of substrate evolution.

\section{CL of NSVT episodes and ICD interventions}

Several studies have found an association between the incidence of NSVTs and the occurrence of appropriate therapies. The $\mathrm{CL}$ of the non-sustained episodes analyzed in such series has been variable: from evaluating only rapid episodes $(\mathrm{CL}<320 \mathrm{~ms})$ [3] to analyzing NSVTs with $C L<400 \mathrm{~ms}[4,6]$. However, in none of them has been studied the impact of CL on the incidence and characteristics of arrhythmias that subsequently produce appropriate therapies. According to our data, unlike the burden, the CL of NSVTs is not a predictor of the subsequent incidence of appropriate therapies. In other words, 


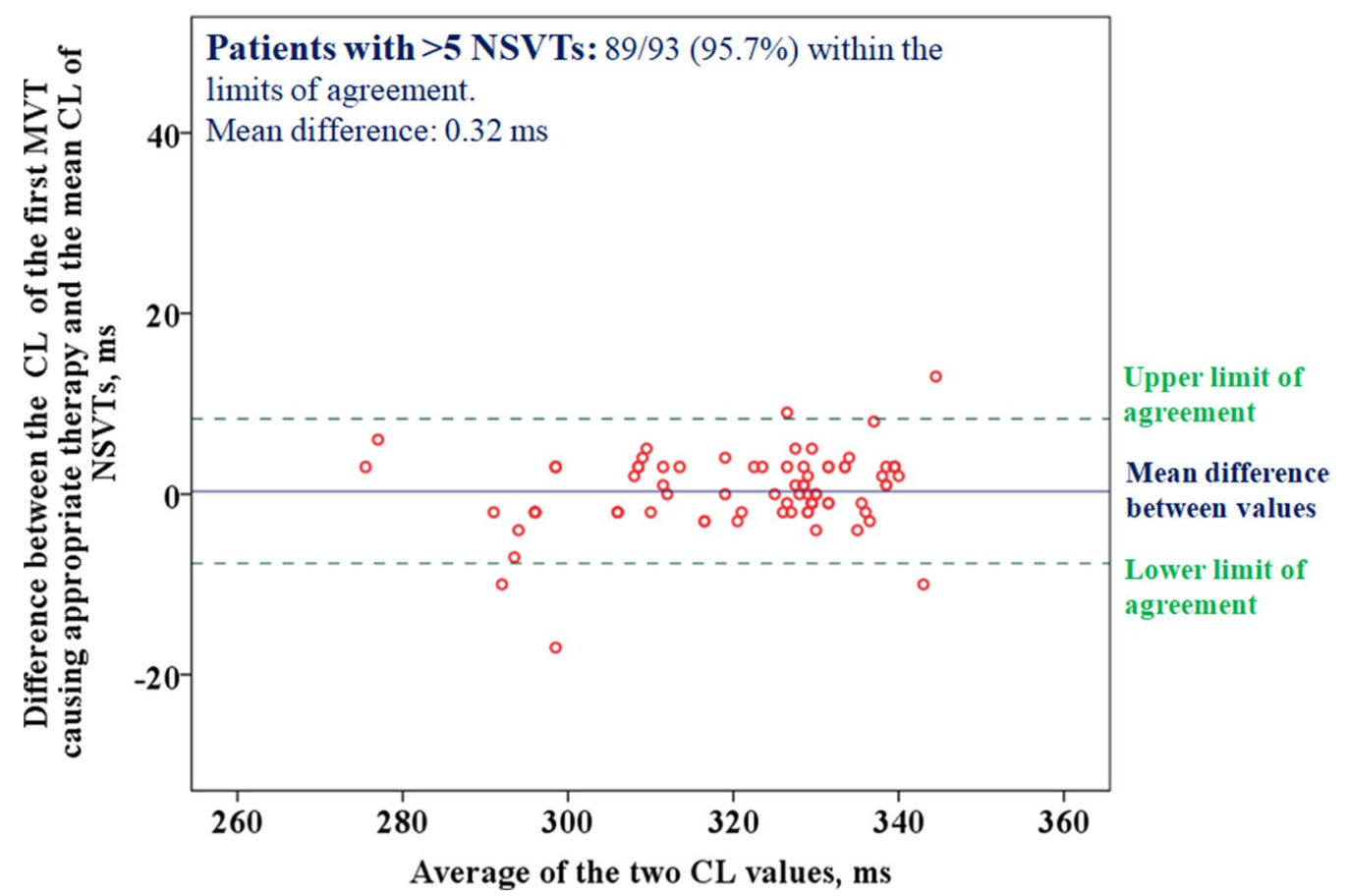

Fig. 3 Bland-Altman graph assessing the agreement between the mean CL of NSVT episodes adjusted for multiples episodes per patient (GEEM) and the $\mathrm{CL}$ of the first MVT that resulted in appropriate therapy among patients with > 5 NSVTs. Each red circle represents a patient. Therefore, in these subjects the $C L$ of the previous non-sustained episodes and the $C L$ of the first subsequent MVT is virtually the same

the burden of NSVTs per patient maintained its independent predictive capacity on the incidence of appropriate therapies over the whole spectrum of mean CL values (Table 3).

Among ICD patients with left ventricular dysfunction, the vast majority of appropriate therapies are caused by MVT. The mean CL of NSVTs is slightly lower than that of the MVT which causes the first appropriate therapy, surely because, among ICD patients, the vast majority of MVTs slow discreetly from detection to therapy [16]. Remarkably, after analyzing the mean CL of the NSVTs and that of the first MVT, which subsequently led to an appropriate therapy, we observed a significant correlation and agreement between the two that was especially robust in subjects with more unsustained episodes. It could be thought that it was the same tachycardia with different duration, a circumstance that is impossible to confirm with our data. In any case, these data indicate that the arrhythmic substrate underlying such individuals is not only more active, but also more specific. In this way, the CL of the NSVTs could be used as a reference for the programming of the detection windows.

\section{VF episodes}

In patients with ICD and left ventricular systolic dysfunction appropriate therapies due to VF are rare, accounting for less than $20 \%$ of events and affecting a minority of subjects [17 18]. Their incidence appears to be similar regardless of etiology (ischemic vs. non-ischemic [19]) and indication (primary vs. secondary prevention [18]). Only individuals with a previous history of VF appear to be more at risk [20].

According to our data, the CL of the NSVTs is a predictor of subsequent appropriate therapies due to VF. In our series, $6.5 \%$ of patients had at least one rapid episode of NSVT $(\mathrm{CL} \leq 300 \mathrm{~ms})$ : one out of such subjects will undergo appropriate therapies for VF in the medium and long term. These data should be taken into account when programming the devices in selected individuals, to avoid delaying detection in the VF zone, since VF episodes produce a rapid hemodynamic impact, including loss of consciousness if not treated quickly.

\section{Limitations}

The detection algorithms used until 2013, although validated in several multicenter studies, may have been too sensitive, so that the incidence of appropriate therapies may be overestimated.

We do not have data on the compared morphology (i.e., far-field electrograms) of the NSVTs versus the subsequent MVT that resulted in appropriate therapy. Although this analysis could have provided additional 


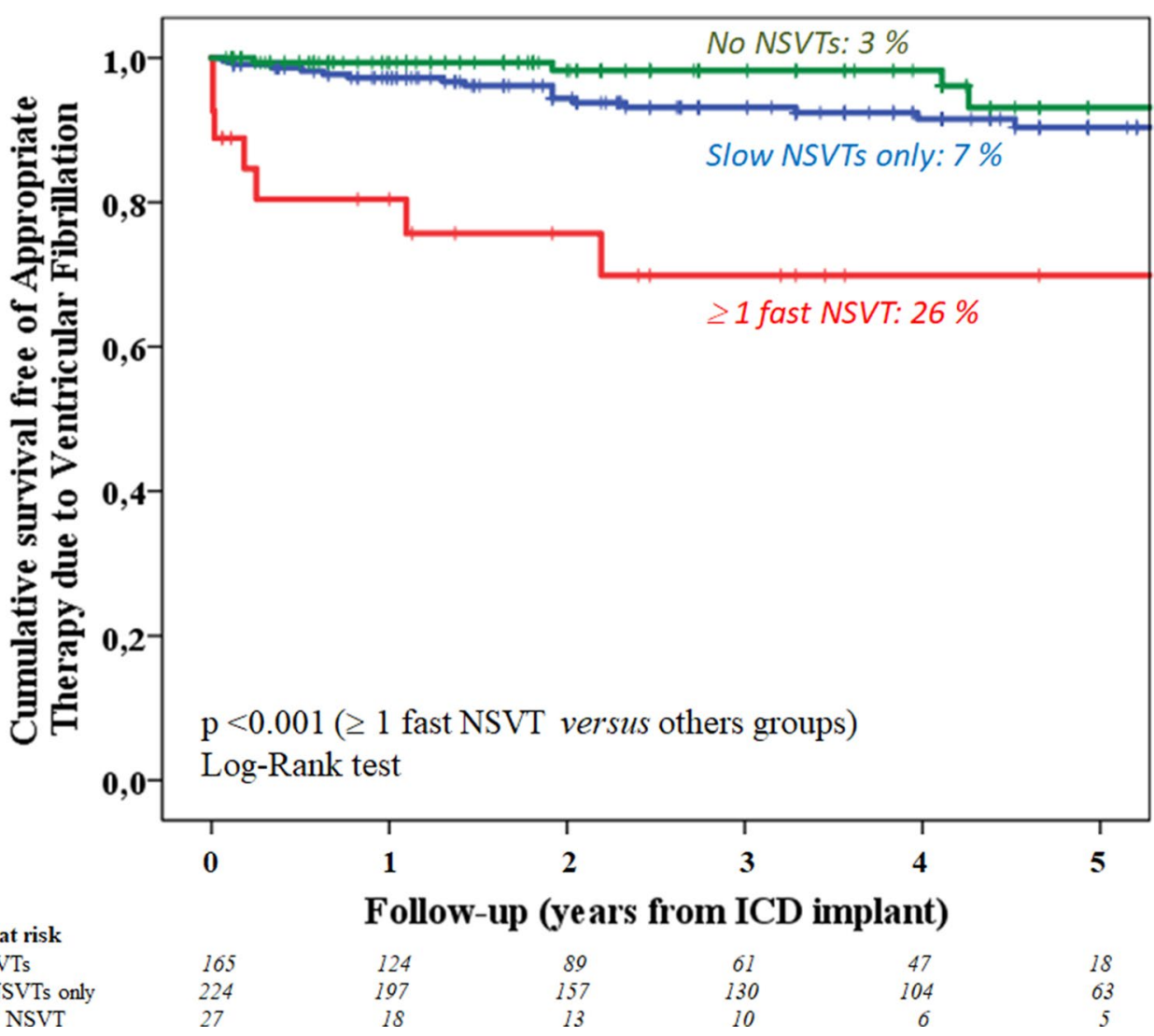

Fig. 4 Kaplan-Meier estimates of the probability of appropriate therapies due to VF according to the previous incidence of fast NSVT episodes. Patients with at least one episode of NSVT with $C L \leq 300 \mathrm{~ms}(n=27)$ had a significantly higher subsequent incidence of appropriate therapies due to VF than subjects without NSVTs $(n=165)$ or with only slow NSVT episodes $(n=224)$

information regarding their anatomical origin, it is often not possible to carry it out because of the change in the morphology of the first beats of the VTs.

Finally, since we only analyzed patients with a single- or dual-chamber ICD, our findings are not applicable to cardiac resynchronization patients.

\section{Conclusions}

Unlike the burden, the CL of NSVTs occurring early after an ICD implant, is not a predictor of having appropriate therapies in general, nor of appropriate therapies due to MVT. However, patients presenting with fast NSVT are at significant risk of appropriate therapies due to VF. In addition, all nonsustained events with a CL within the range explored in this study have prognostic impact.

There is some specificity between the mean CL of such NSVT episodes and that of the ventricular arrhythmias that subsequently lead to appropriate therapies, which may be useful when programming the devices.

Future efforts will need to be directed to determine which patients may be candidates for either antiarrhythmic drug therapy or catheter ablation for the elimination NSVT episodes and to assess whether arrhythmia suppression can improve outcomes in these patients.

\begin{abstract}
Abbreviations
NSVTs: Nonsustained ventricular tachycardias; ICD: Impantable cardioverterdefibrillator; CL: Cycle length; VT: Ventricular tachycardia; VF: Ventricular fibrillation; MVT: Monomorphic ventricular tachycardia; LVEF: Left ventricular ejection fraction; ATP: Antitachycardia pacing; GEEM: Generalized estimating equations method; HR: Hazard ratio; OR: Odds ratio.
\end{abstract}

\section{Acknowledgements}

The authors wish to thank Dr. Angel Arenal for his critical review of the manuscript.

\section{Authors' contributions}

JJ-C: Concept, drafting article, Statistics, Approval of article. OD: Data collection, Data interpretation, Critical revisión of article. AO: Data collection, Data interpretation, Critical revisión of article. JP: Data collection, Data interpretation, Critical revisión of article. JCC: Data collection, Data interpretation, Critical revisión of article. JH: Data interpretation, Approval of article. JM: Data interpretation, Approval of article. MSG: Data interpretation, Approval of article. PLS: Data interpretation, Approval of article. All authors read and approved the final manuscript.

\section{Funding}

The study is not funded by third parties. 


\section{Availability of data and materials}

All material in the article is the property of the authors; no third-party permission is required for publication. The datasets used and/or analyzed during the current study are available from the corresponding author on reasonable request.

\section{Declarations}

\section{Ethics approval and consent to participate}

The study has the approval of the "Comité de Estudios y Ensayos Clínicos del Servicio de Cardiología del Hospital Universitario de Salamanca". All patients gave their written consent. The study complied with the Declaration of Helsinki.

\section{Consent for publication}

Not applicable.

\section{Competing interests}

The authors have no competing interests as defined by BMC, or other interests that might be perceived to influence the results and/or discussion reported in this paper.

Received: 23 November 2020 Accepted: 26 May 2021

Published online: 31 May 2021

\section{References}

1. Doval HC, Nul DR, Grancelli HO, et al. Nonsustained ventricular tachycardia in severe heart failure. Independent marker of increased mortality due to sudden death. GESICA-GEMA Investigators. Circulation. 1996;94(12):3198-203.

2. Verma A, Sarak B, Kaplan AJ, et al. Predictors of appropriate implantable cardioverter defibrillator (ICD) therapy in primary prevention patients with ischemic and nonischemic cardiomyopathy. Pacing Clin Electrophysiol. 2010;33(3):320-9.

3. Chen J, Johnson G, Hellkamp AS, et al. Rapid-rate nonsustained ventricular tachycardia found on implantable cardioverter-defibrillator interrogation: relationship to outcomes in the SCD-HeFT (Sudden Cardiac Death in Heart Failure Trial). J Am Coll Cardiol. 2013;61(21):2161-8.

4. Jimenez-Candil J, Hernandez J, Perdiguero P, et al. Prognostic significance of nonsustained ventricular tachycardia episodes occurring early after implantable cardioverter-defibrillator implantation among patients with left ventricular dysfunction. Am J Cardiol. 2016;118(10):1503-10.

5. Zhou X, Gunderson BD, Olson WH. Incidence of nonsustained and sustained ventricular tachyarrhythmias in patients with an implantable cardioverter defibrillator. J Cardiovasc Electrophysiol. 2004;15(1):14-20.

6. Makimoto $\mathrm{H}$, Zielke S, Clasen L, et al. Clinical significance of precedent asymptomatic non-sustained ventricular tachycardias on subsequent ICD interventions and heart failure hospitalization in primary prevention ICD patients. Eur J Med Res. 2020;25(1):5.

7. Garcia-Alberola A, Yli-Mayry S, Block M, et al. RR interval variability in irregular monomorphic ventricular tachycardia and atrial fibrillation. Circulation. 1996;93(2):295-300.
8. Swerdlow CD, Chen PS, Kass RM, Allard JR, Peter CT. Discrimination of ventricular tachycardia from sinus tachycardia and atrial fibrillation in a tiered-therapy cardioverter-defibrillator. J Am Coll Cardiol. 1994;23(6):1342-55.

9. Liang K, Zeger S. Longitudinal data analysis using generalized linear models. Biometrika. 1986;73:13-22.

10. Quast ABE, Brouwer TF, Tjong FVY, Wilde AAM, Knops RE. Clinical parameters to optimize patient selection for subcutaneous and transvenous implantable defibrillator therapy. Pacing Clin Electrophysiol. 2018:41:990-5.

11. Josephson ME. Recurrent ventricular tachycardia. In: Josephson ME, editor. Clinical cardiac electrophysiology. Techniques and interpretations, vol. 1. 3rd ed. Philadelphia: Lippincott Williams \& Wilkins; 2002. p. 435-9.

12. Callans DJ, Josephson ME. Ventricular tachycardia in patients with coronary artery disease. In: Zipes DP, editor. Cardiac electrophysiology. From cell to bedside. Philadelphia: Sauders; 2004. p. 569-74.

13. Berte B, Sacher F, Venlet J, et al. VT recurrence after ablation: incomplete ablation or disease progression? A Multicentric European Study. J Cardiovasc Electrophysiol. 2016;27(1):80-7.

14. Mittal S, Lomnitz D, Mirchandani S, et al. Prognostic significance of nonsustained ventricular tachycardia after revascularization. J Cardiovasc Electrophysiol. 2002;13(4):342-6.

15. Fujii A, Nagashima K, Kumar S, et al. Significance of inducible nonsustained ventricular tachycardias after catheter ablation for ventricular tachycardia in ischemic cardiomyopathy. Circ Arrhythm Electrophysiol. 2017;10:e005005. https://doi.org/10.1161/CIRCEP.117.005005.

16. Jimenez-Candil J, Hernandez J, Martin A, et al. Influence of cycle length variations on antitachycardia pacing effectiveness among ICD patients. Heart Rhythm. 2013;10(2):207-13.

17. Anthony R, Daubert JP, Zareba W, et al. Mechanisms of ventricular fibrillation initiation in MADIT II patients with implantable cardioverter defibrillators. Pacing Clin Electrophysiol. 2008;31(2):144-50.

18. Sweeney MO, Wathen MS, Volosin K, et al. Appropriate and inappropriate ventricular therapies, quality of life, and mortality among primary and secondary prevention implantable cardioverter defibrillator patients: results from the Pacing Fast VT REduces Shock ThErapies (PainFREE Rx II) trial. Circulation. 2005;111(22):2898-905.

19. Cheng A, Joung B, Brown ML, et al. Characteristics of ventricular tachyarrhythmias and their susceptibility to antitachycardia pacing termination in patients with ischemic and nonischemic cardiomyopathy: a patientlevel meta-analysis of three large clinical trials. J Cardiovasc Electrophysiol. 2020:31(10):2720-6.

20. Raitt MH, Klein RC, Wyse DG, et al. Comparison of arrhythmia recurrence in patients presenting with ventricular fibrillation versus ventricular tachycardia in the Antiarrhythmics Versus Implantable Defibrillators (AVID) trial. Am J Cardiol. 2003;91(7):812-6.

\section{Publisher's Note}

Springer Nature remains neutral with regard to jurisdictional claims in published maps and institutional affiliations.

Ready to submit your research? Choose BMC and benefit from

- fast, convenient online submission

- thorough peer review by experienced researchers in your field

- rapid publication on acceptance

- support for research data, including large and complex data types

- gold Open Access which fosters wider collaboration and increased citations

- maximum visibility for your research: over $100 \mathrm{M}$ website views per year

At $\mathrm{BMC}$, research is always in progress.

Learn more biomedcentral.com/submissions 